\title{
Aspects of Crack Growth in Single-Crystal Nickel-Base Superalloys
}

\author{
Christian Busse
}

I.U UNNKDONG

Division of Solid Mechanics

Linköping University

SE-581 83 Linköping, Sweden

Linköping, December 2017 
Cover:

Front: Anisotropic stress response of an FE-simulation of an uncracked DCT specimen. Back: Stress response at the crack tip of an FE-simulation of a cracked DCT specimen.

Printed by:

LiU-Tryck, Linköping, Sweden, 2017

ISBN: 978-91-7685-395-5

ISSN: 0280-7971

Distributed by:

Linköping University

Division of Solid Mechanics

SE-581 83 Linköping, Sweden

\section{(C) 2017 Christian Busse}

This document was prepared with $\mathrm{LT}_{\mathrm{E}} \mathrm{X}$, November 14, 2017

No part of this publication may be reproduced, stored in a retrieval system, or be transmitted, in any form or by any means, electronic, mechanical, photocopying, recording, or otherwise, without prior permission of the author. 


\section{Preface}

The work presented in this Licentiate of Engineering thesis has been generated at the Division of Solid Mechanics at Linköping Universtiy and is part of the research project KME-702. The research has been funded by the Swedish Energy Agency and Siemens Industrial Turbomachinery AB through the Research Consortium of Materials Technology for Thermal Energy Processes, the support of which is greatly acknowledged. The research project concerns the fields of mechanical testing, microstructure investigations and modelling. This variety gave me the opportunity to learn something new in many different fields almost every day.

This said, I would especially like to thank my main supervisor Associate Prof. Daniel Leidermark $^{1}$, who is always taking himself the time to help and is a great personality, both professionally and privately. Furthermore, I would like to thank my project group; Prof. Kjell Simonsson ${ }^{1}$, Lic. Eng. Björn Sjödin ${ }^{2}$, Lic. Eng. Per Almroth ${ }^{2}$, Dr. David Gustafsson $^{2}$, Prof. Johan Moverare ${ }^{3}$, M.Sc. Patrik Rasmusson ${ }^{2}$ and M.Sc. Frans Palmert ${ }^{2}$ for all the valuable discussions and input.

Furthermore, I would like to thank my friend and fellow PhD student J-L, who helped me with many fruitful discussions and makes the $\mathrm{PhD}$ life more joyful.

Finally, I would like to thank Nathalie, who, even though we had to part ways, has always supported me and was always there for me. In a way, I am where I am today because of you. I will always be grateful for that and I will never forget you. Thank you!

Christian Busse

Linköping, December 2017

\footnotetext{
${ }^{1}$ Division of Solid Mechanics, Linköping University

${ }^{2}$ Siemens Industrial Turbomachinery AB

${ }^{3}$ Division of Engineering Materials, Linköping University
} 



\section{Abstract}

This Licentiate of Engineering thesis is a product of the results generated in the research project KME-702, which comprises modelling, microstructure investigations and material testing of cast nickel-base superalloys.

The main objective of this work is to model the fatigue crack propagation behaviour in single-crystal nickel-base superalloys. To achieve this, the influence of the crystal orientations on the cracking behaviour is assessed. The results show that the crystal orientation is strongly affecting the material response and must be accounted for. Furthermore, a linear elastic crack driving force parameter suitable for describing crystallographic cracking has been developed. This parameter is based on resolved anisotropic stress intensity factors and is able to predict the correct crystallographic cracking plane after a transition from a Mode I crack. Finally, a method to account for inelastic deformations in a linear elastic fracture mechanics context was investigated. A residual stress field is extracted from an uncracked finite-element model with a perfectly plastic material model and superimposed on the stress field from the cracked model with a linear elastic material model to account for the inelastic deformations during the determination of the crack driving force. The modelling work is validated by material testing on two different specimen geometries at different temperatures.

This Licentiate of Engineering thesis consists of two parts, where Part I gives an introduction and background to the research area, while Part II consists of three papers. 



\section{Zusammenfassung}

Dieses Lizentiat der Ingenieurwissenschaften ist im Rahmen des Forschungsprojekts KME-702 entstanden, welches Modellierung, Mikrostrukturuntersuchungen und Materialtests von gegossenen nickelbasierten Superlegierungen umfasst.

Das Hauptziel dieser Arbeit ist die Modellierung der Ermüdungsrissausbreitung in einkristallinen nickelbasierten Superlegierungen. Um dieses zu erreichen, wurde der Einfluss der Kristallorientierungen auf das Rissverhalten untersucht. Die Ergebnisse zeigen, dass die Kristallorientierung das Materialverhalten stark beeinflusst und daher berücksichtigt werden muss. Darüber hinaus wurde ein linear elastischer Rissantriebskraftparameter entwickelt, der zum Beschreiben von kristallographischen Rissen geeignet ist. Dieser Parameter basiert auf aufgelösten anisotropen Spannungsintensitätsfaktoren und ist in der Lage, die korrekte kristallographische Rissebene nach einem Übergang von einem Modus I Riss vorherzusagen. Abschließend wird in einem linear-elastisch bruchmechanischen Kontext eine Methode untersucht, die nichtelastischen Deformationen bei der Bestimmung der Rissantriebskraft zu berücksichtigen. Dazu wird aus einem Finite-Elemente Modell, welches keinen Riss aufweist und mit einem perfekt plastischen Materialmodell beschrieben wird, das Restspannungsfeld extrahiert und dem Spannungsfeld überlagert, welches aus dem Modell mit Riss unter Verwendung eines linear elastischen Materialmodells erzeugt wurde. Die Modellierung wird durch Materialtests an zwei verschiedenen Probengeometrien bei unterschiedlichen Temperaturen validiert.

Dieses Lizentiat der Ingenieurwissenschaften besteht aus zwei Teilen, wobei Teil I eine Einführung und einen Hintergrund in das Forschungsgebiet gibt, während Teil II aus drei Forschungsartikeln besteht. 



\section{Sammanfattning}

Denna licentiatavhandling är en produkt av resultat som genererats i forskningsprojektet KME-702, och omfattar modellering, mikrostrukturundersökningar och materialprovning av gjutna nickelbaserade superlegeringar.

Huvudsyftet med detta arbete är att modellera sprickförloppet under utmattning i enkristallina nickelbaserade superlegeringar. För att uppnå detta har kristallorienteringens inverkan på sprickbeteendet utvärderats. Resultaten visar att kristallorienteringen har en stark inverkan på materialbeteendet, således måste hänsyn till denna tas. Dessutom har en linjär-elastisk sprickdrivkraftsparameter lämplig att beskriva kristallografisk sprickbildning utvecklats. Denna parameter är baserad på anisotropa spänningsintensitetsfaktorer på kristallplan och kan prediktera det korrekta kristallografiska sprickplanet efter övergång från Modus I spricka. Slutligen har undersökts en metod för att ta hand om inelastiska deformationer i en linjär-elastisk brottmekanikskontext. Ett restspänningsfält extraherades från en osprucken finita element modell med en ideal plastisk materialmodell. Denna överlagrades på spänningsfältet från den spruckna modellen, som analyserades med en linjär-elastisk materialmodell, för att ta hänsyn till de inelastiska deformationerna vid bestämning av sprickdrivkraften. Modelleringsarbetet validerades genom materialprovning på två olika provgeometrier vid olika temperaturer.

Licentiatavhandlingen består av två delar, där del I ger en introduktion och bakgrund till forskningsområdet medan del II består av tre papper. 



\section{List of papers}

In this thesis, the following papers have been included:

I. C. Busse, J. Homs, D. Gustafsson, F. Palmert, B. Sjödin, J. J. Moverare, K. Simonsson, D. Leidermark (2016). A finite element study of the effect of crystal orientation and misalignment on the crack driving force in a single-crystal superalloy, Proceedings of the ASME Turbo Expo, Volume 7A-2016

II. C. Busse, F. Palmert, B. Sjödin, P. Almroth, D. Gustafsson, K. Simonsson, D. Leidermark (2017). Prediction of crystallographic cracking planes in a singlecrystal nickel-base superalloy, In manuscript.

III. C. Busse, D. Gustafsson, P. Rasmusson, B. Sjödin, J. J. Moverare, K. Simonsson, D. Leidermark (2015). Three dimensional LEFM-prediction of fatigue crack propagation in a gas turbine disc material at component near conditions, Journal of Engineering for Gas Turbines and Power, Volume 138, Issue 4, Article Number 042506

\section{Note}

The appended papers have been reformatted to fit the layout of the thesis.

\section{Own contribution}

The mechanical experiments have been done at Linköping University by M.Sc. Frans Palmert and Prof. Johan Moverare and at the Metcut Research facilities in Cincinnati, Ohio, USA. The test evaluations have been done by Frans Palmert and myself and all the modelling has been done by me. Microscopy and test related images have been done by Frans Palmert. Furthermore, the major part of the writing, in the above papers, has been performed by me. For the work presented in this Lic. Eng. thesis, I am to hold the primary responsibility. 



\section{Contents}

Preface iii

Abstract $\quad$ v

Zusammenfassung vii

$\begin{array}{ll}\text { Sammanfattning ix } & \text { ix }\end{array}$

List of papers $\quad$ xi

Contents $\quad$ xiii

Part I - Theory and Background 1

1 Introduction 3

1.1 Aim of the work . . . . . . . . . . . . . . . 4

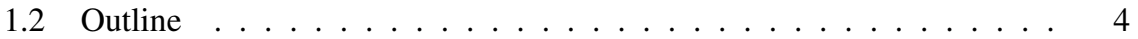

2 Nickel-Base Superalloys 5

2.1 Single-crystals . . . . . . . . . . . . . . . 5

3 Testing 7

3.1 Crystallographic orientations .................... 7

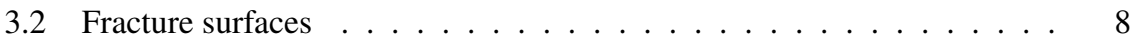

4 Fatigue Crack Propagation $\quad 11$

4.1 Linear fatigue crack propagation . . . . . . . . . . . . . . . . . . 11

4.2 Stress intensity factor . . . . . . . . . . . . . . . . . . 12

4.2 .1 M-Integral . . . . . . . . . . . . . . . 13

4.3 Crystallographic crack propagation . . . . . . . . . . . . . . 15

4.4 Crystallographic crack driving force . . . . . . . . . . . . . . . . 15

4.5 FE-context . . . . . . . . . . . . . . . . . 16

4.6 Handling inelasticity . . . . . . . . . . . . . . . 17 
5 Review of Appended Papers 19

6 Outlook 21

$\begin{array}{ll}\text { Part II - Appended Papers } & 27\end{array}$

Paper I: A finite element study of the effect of crystal orientation and misalignment on the crack driving force in a single-crystal superalloy . . . 31

Paper II:Prediction of crystallographic cracking planes in a single-crystal nickel-base superalloy . . . . . . . . . . . . . . . . . 47

Paper III: Three dimensional LEFM-prediction of fatigue crack propagation in a gas turbine disc material at component near conditions . . . . . . 79 


\section{Part I}

\section{Theory and Background}





\section{Introduction}

In the current energy market more and more attention is given to renewable energy sources, like wind and solar power. It seems almost inevitable that renewable energies will dominate the energy market of the future. The current problem with these inherently intermittent energy sources is that it is impossible to store the generated energy efficiently and use it during the time when energy cannot be produced, e.g. when the wind is not blowing or the sun is not shining. An overproduction of energy can, for instance, be stored as hydrogen, which is a potential fuel for stationary industrial gas turbines. An industrial gas turbine can act as a good solution as an energy producer with its fast start-up and shut-down times when there is a need for energy that can be dispatched at the request of the power grid operator [1]. However, most land-based gas turbines have traditionally been designed for base load operation and might undergo significant damage due to change in operation conditions, i.e. more cyclic conditions. Hence, a need for estimating the damage and designing the gas turbine for increased cyclic loading conditions is vital for the future energy demands.

In order to increase the energy output, higher thermal efficiency of the gas turbines is needed. Thus, the development strives towards always rising operating temperatures [2], leading to increasing requirements of the used materials to resist the high temperatures. In all the regions of a gas turbine the blades of the first turbine stage are the components that have to withstand the highest temperatures where also high mechanical loads are present. These components are often cast from nickel-base superalloys in the form of singlecrystals. The material anisotropy of single-crystal materials adds an extra dimension of complexity to the modelling, testing and understanding of the fracture mechanisms [3-11]. The service life of many hot components is not fully restricted by the number of cycles to crack initiation, which means that a certain amount of crack propagation is allowed before the component has to be replaced in service. Especially close to stress concentrations, one has to rely on stable and predictable crack propagation. Such damage tolerant approaches demand accurate predictions of the crack growth. The accumulated effect of such stress and temperature cycles leads to the possibility of failure by fatigue cracks and especially thermomechanical fatigue (TMF).

This Licentiate of Engineering thesis is part of the research project KME-702 and mainly focuses on crack propagation modelling in nickel-base superalloys in singlecrystal form. Furthermore, a method to handle inelastic deformations in a Linear Elastic Fracture Mechanics (LEFM) context during crack propagation is presented. This method is based on residual stress fields and has been shown to give good fatigue life predictions for a polycrystalline nickel-base superalloy and it is expected to be applicable to singlecrystals. 
Previous research has shown that the deformation in single-crystal materials is often localized to a number of crystallographic deformation bands and that cracks follow these bands more easily [12]. Thus, the cracks cannot be expected to follow the conventional Mode I Stress Intensity Factor (SIF) dependency (i.e. crack growth perpendicular to the applied load) as commonly observed in conventional materials [13-18]. Hence, an appropriate Crack Driving Force (CDF) parameter needs to be developed to be able to describe the observed fracture behaviour in single-crystal nickel-base superalloys. Advances in the understanding of the fracture properties of single-crystal nickel-base superalloys can lead to an increased life span, a reduction of conservative design and therefore a prolongation of service intervals, the ability to support a wider fuel flexibility as well as an improvement of the capacity for cyclic operation of the next generation of advanced gas turbines for energy production.

\subsection{Aim of the work}

The aim of this project is to develop a methodology for predicting the transition of cracking mode, from perpendicular to the loading direction (Mode I) to cracking along the crystallographic slip planes, and also an evaluation of the crack propagation rate for the considered cracking mode. It is desired to predict on which slip plane the crack will grow, which is the focus of this work, when the transition happens and also how fast the crystallographic crack will grow.

\subsection{Outline}

Part I of the thesis gives an introduction to nickel-base superalloys, some background of fracture mechanics and fatigue as well as crack propagation modelling in these materials. Furthermore, an overview of the performed experiments is given. Part II contains the three papers produced so far in the project. 


\section{Nickel-Base Superalloys}

Nickel-base superalloys are often found in critical components of gas turbines due to their superior mechanical strength and creep resistance at elevated temperatures. They are used in components in the hottest sections exposed to the highest loads, since they show great resistance to mechanical and chemical degradation at temperatures close to their melting point [2]. These alloys usually contain at least ten different alloying elements, where the base is nickel. This is due to the Face-Centered-Cubic (FCC) crystal structure of nickel, which makes it tough and ductile and also stable so that no phase transformation occurs during a temperature increase from room temperature until its melting point. Inclusion of chromium and aluminium in nickel-base superalloys increases the resistance against corrosion and oxidation, respectively.

The material properties of the superalloys are, as stated earlier, mainly governed by the microstructure and its phase composition. The most common phases are gamma $\gamma$ and gamma prime $\gamma^{\prime}$. The $\gamma$-phase is the matrix and has FCC structure due to the fact that the nickel resides there and the $\gamma^{\prime}$-phase is the principal strengthening phase [19].

\subsection{Single-crystals}

Nickel-base superalloys can be cast in monocrystalline form, i.e. as single-crystals. This means that only one grain is allowed to grow into the casting form during the casting process and thus eliminating the grain boundaries. This leads to improved the creep properties compared to poly-crystal nickel-base superalloys. The absence of grain boundaries also results in an anisotropic material behaviour. In case of single-crystal nickel-base superalloys a cubic anisotropy is present. Inelastic deformations occur along the so called close-packed planes or discrete slip planes. In materials with FCC crystal lattice structure there are four $\{111\}$ (Miller notation) slip planes. On each slip plane there exist three primary slip direction as of $\langle 011\rangle$, which results in twelve slip systems.

These materials exhibit not only elastic but also plastic anisotropy as well as tension and compression asymmetry. In addition, the hardening behaviour can be approximated to be perfectly-plastic [3]. One nickel-base single-crystal that was considered in this study is STAL15 [20]. It shows strength and other properties comparable to available commercial single-crystal materials used for similar applications, but with improved oxidation and corrosion resistance [21, 22]. 



\section{Testing}

In order to gain a better understanding of the crack growth behaviour and its effects in single-crystal nickel-base superalloys, experiments on two different specimen types were performed; a surface flawed fatigue crack growth specimen of Kb-type [23] and a Disc Shaped Compact Tension (DCT) specimen, see Fig. 1. The tests were done according to ASTM E647 [24] and the crack lengths were monitored using direct current potential drop measurements. Low-Cycle Fatigue (LCF) test data was generated for the temperature of $500^{\circ} \mathrm{C}$. It should be noted that no fatigue crack growth rate data is presented in this thesis. A challenge in this context is the determination of the crack growth rate associated with the crystallographic cracking mode, where crack length and cracked surface area can deviate substantially from conventional Mode I cracks. Hence, this test data will be used to finalise a suitable Paris' law expression, which considers implications of fatigue crack growth in single-crystal nickel-base superalloys, and enables the prediction of correct fatigue life.
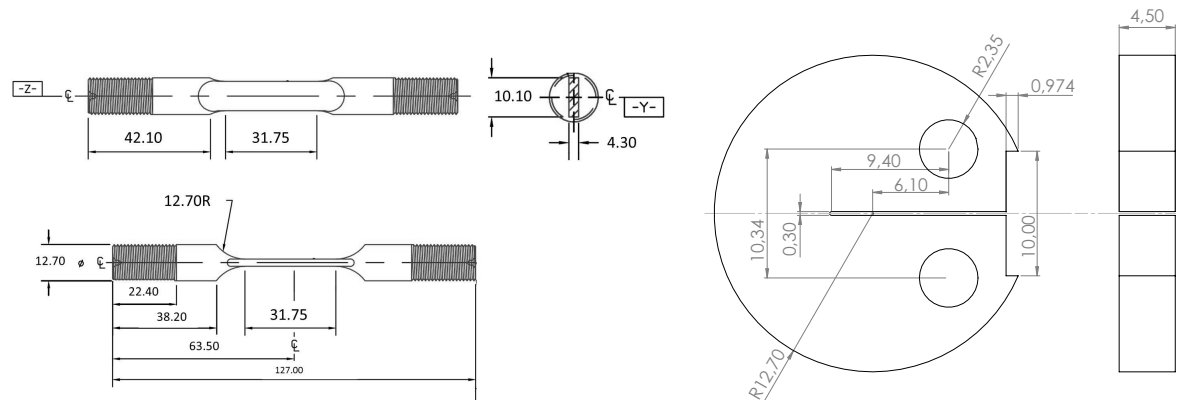

(a)

(b)

Figure 1: Technical drawing of (a) the Kb specimen and (b) the DCT specimen. Dimensions in $\mathrm{mm}$.

\subsection{Crystallographic orientations}

During the casting process it is difficult to control the growth direction of the crystal and misalignments from the casting direction are almost impossible to eliminate. The crystallographic orientation has a substantial influence on the stress allocation and thus the 


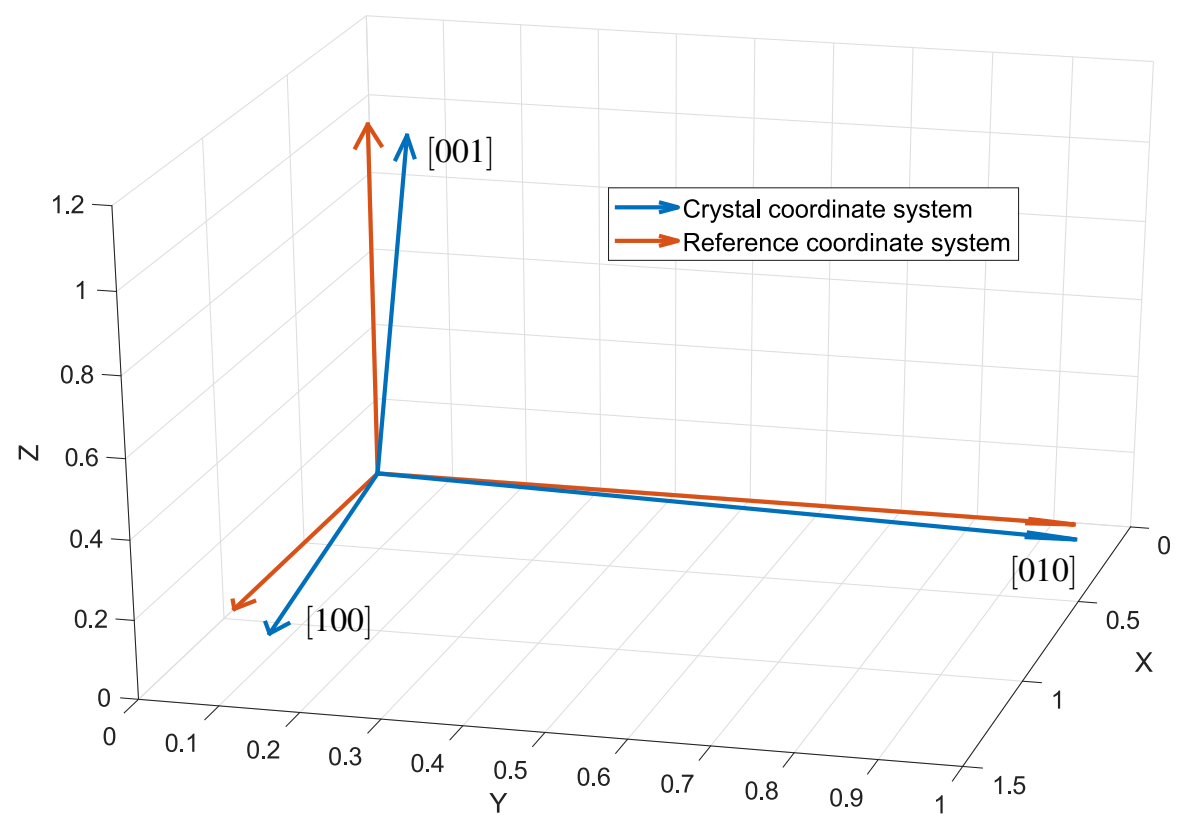

Figure 2: Representation of the crystal coordinate system.

crack growth behaviour $[16,20,25,26]$. In order to model the correct material response, it is important to know the correct crystallographic orientation, as the misalignments from the casting process are present in the specimens. In order to determine the correct crystallographic orientation in each specimen, they were cut at three perpendicular planes, where the angle of the projections of the dendrites on each of the cutting surfaces was measured. The measured angles were post-processed to find the best fit of the crystallographic orientation using an optimization routine. This had to be done to determine an orthogonal Cartesian coordinate system, since all measured angles are not equal for all the different dendrites on the same surface; this due to e.g. the inhomogeneous solidification of the material during the manufacturing process. For further details the reader is referred to Paper II. An example regarding the material misalignments is illustrated in Fig. 2, where the orientation of the crystal coordinate system is shown together with the reference coordinate system (primary crystallographic orientation). The computed crystallographic orientation is then used to model the cracking behaviour more accurately in the corresponding test specimen.

\subsection{Fracture surfaces}

After the experiments, the fracture surfaces were evaluated in order to quantify the crack length where the transition of cracking mode occurred, $c f$. Fig. 3 a for a $\mathrm{Kb}$ specimen. Furthermore, the fracture surfaces were 3D-scanned to determine on which 
$\{111\}$ crystallographic planes the crack transitioned to and grew on during the tests. A 3D-scanned fracture surface can be seen in Fig. 3b, where the green planes are the two active crystallographic planes $((\overline{1} 1 \overline{1})$ and $(\overline{1} \overline{1} 1))$.

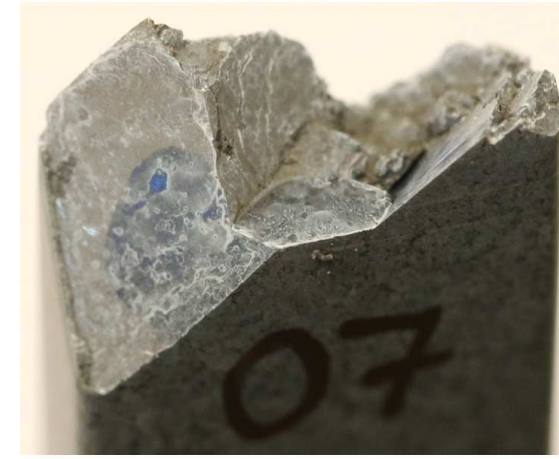

(a)

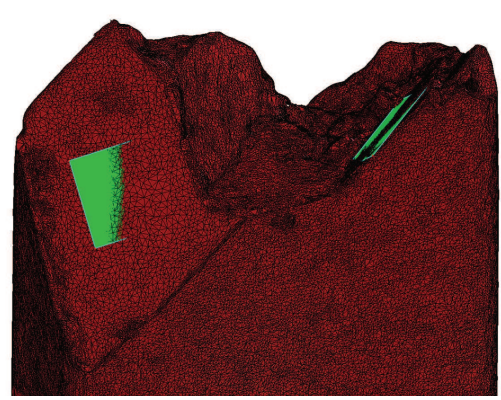

(b)

Figure 3: (a) Fracture surface of a Kb specimen (b) with its 3D-representation. 



\section{Fatigue Crack Propagation}

Fatigue occurs at repeated cyclic loading and is commonly divided into several different categories, e.g. High-Cycle-Fatigue (HCF), LCF or TMF. LCF occurs when the local stress due to mechanical loads is at or beyond the yield limit and consequently HCF when it is below. The temperature is assumed to be constant for LCF and HCF, whereas in $\mathrm{TMF}$ also the temperature is cycled with or without a phase difference to the mechanical load.

Often, the allowed life time of a component is restricted only to the time until crack initiation. By also incorporating stable crack propagation the time in operation could be increased significantly. Fatigue crack propagation is often neglected, since it is more difficult in terms of modelling and testing, especially for anisotropic materials as singlecrystal nickel-base superalloys, although a majority of the life time being spent may be during propagation.

\subsection{Linear fatigue crack propagation}

In order to estimate the cyclic life-time after crack initiation, a crack propagation law is needed. The most widely used is Paris' law developed by Paris et al. [27, 28], which relates the crack growth rate to the SIF-range:

$$
\frac{d a}{d N}=C \cdot(\Delta K)^{m}
$$

where $C$ and $m$ are the empirical constants based on the material and $\Delta K=K_{\max }-$ $K_{\min } . \Delta K$ may be interchanged with any other appropriate CDF parameter. The crack propagation rate is generally plotted in a double logarithmic diagram over the SIF-range, $c f$. Fig. 4. A material usually shows three distinct regions of crack growth behaviour, as seen in the plot. In region I the crack propagation rates are very low. Below the threshold value $\Delta K_{\text {th }}$ no crack growth is expected. Region II assumes stable macroscopic crack growth. In region III the fatigue crack growth is considered unstable, which leads to very high crack growth rates. The critical value for this region is the fracture toughness which, at plane strain is denoted $K_{\mathrm{Ic}}$. When $K_{\mathrm{Ic}}$ is reached, a failure of the component is imminent. Region II in Fig. 4 is typically linear in the log-log scale and can be described by Eq. 1. The fatigue life of a component can then be calculated by integrating Eq. 1 .

In order to make a reliable estimation of the fatigue life using Paris' law, an appropriate CDF parameter must be determined and is therefore of high importance. 


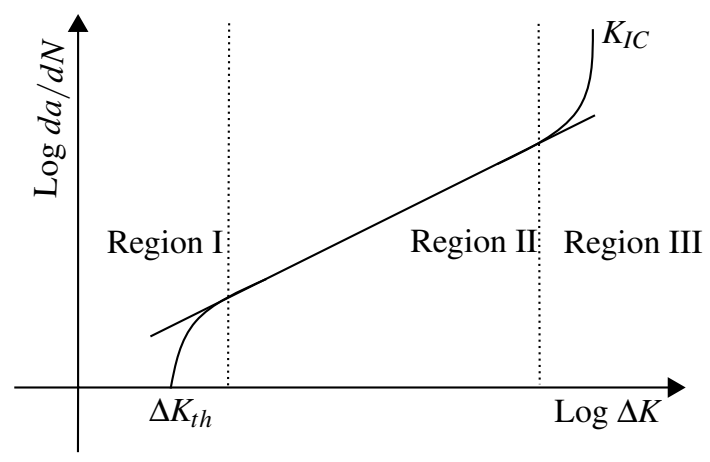

Figure 4: Fatigue crack propagation regions.

\subsection{Stress intensity factor}

A very commonly used $\mathrm{CDF}$, as discussed above, is the SIF, which is a measure to describe the stress state in front of the crack tip, at the stress singularity. The conventional SIFs are categorized into $K_{I}, K_{I I}$ and $K_{I I I}$, representing the three modes of fracture, i.e. opening, in-plane shear and out-of-plane shear, respectively and can be defined either by means of far-field stresses or local stresses around the crack tip. In terms of far field stresses the Mode I SIF can be defined as:

$$
K_{I}=\sigma_{\infty} \sqrt{\pi a} \cdot f
$$

where $\sigma_{\infty}$ is the far-field stress, $a$ is the crack length and $f$ is a geometry function. This can only be used if the geometry function is known by, for instance, handbook solutions. In terms of local stresses the SIFs are defined for $\theta=0, c f$. Fig. 5, by:

$$
\begin{aligned}
& K_{I}=\sqrt{2 \pi r} \cdot \sigma_{y y} \\
& K_{I I}=\sqrt{2 \pi r} \cdot \tau_{y x} \\
& K_{I I I}=\sqrt{2 \pi r} \cdot \tau_{y z},
\end{aligned}
$$

where $r$ is defined on a plane perpendicular to the crack front as illustrated in Fig. 5 and $\sigma_{y y}, \tau_{y x}$ and $\tau_{y z}$ are local stresses at the distance $r$ from the crack tip [29]. The difficulty with this solution is, that the local stresses have to be known and are often difficult to determine in the presence of a crack. Another approach to calculate the SIFs in linear elastic materials is by means of the energy release rate $G$ developed by Irwin [30], which relates the change of potential energy $\Pi$ to the crack area $A$. 


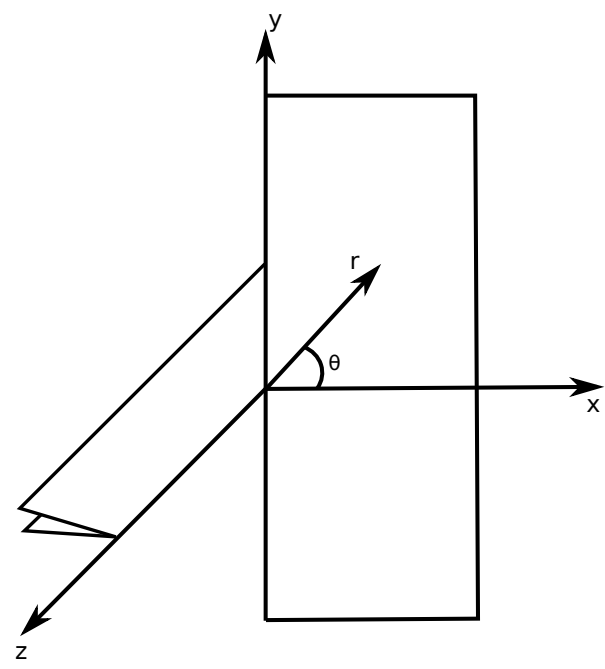

Figure 5: Crack front cartesian and cylindrical coordinate system.

$$
G_{I}=\alpha K_{I}^{2}, \quad G_{I I}=\alpha K_{I I}^{2},
$$

where

$$
\alpha=\left\{\begin{array}{cc}
\left(1-v^{2}\right) / E & \text { for } \text { plane strain } \\
1 / E & \text { for } \text { plane stress, }
\end{array}\right.
$$

and where

$$
G=-\frac{d \Pi}{d A}
$$

\subsubsection{M-Integral}

The M-Integral developed by Yau et al. [31] has indirectly been used throughout this work to calculate the SIFs. It has developed from the J-Integral, to extract the SIFs for the three fracture modes from the global energy release rate. In the following, the 2D-formulation for isotropic materials is briefly explained. The concept can then be extended into a 3D-context for generally anisotropic materials [32, 33]. The J-Integral is given by:

$$
J=\int_{\Gamma}\left(W d y-T_{i} \frac{\partial u_{i}}{\partial x}\right) d s,
$$

where $W=1 / 2 \sigma_{i j} \varepsilon_{i j}$ is the strain energy density, $\Gamma$ is the integration path, $d s$ is a length increment along $\Gamma, T_{i}=\sigma_{i j} n_{j}$ is the traction vector and $u_{i}$ is the displacement vector as illustrated by the arbitrary contour around the crack tip in Fig. 6. 


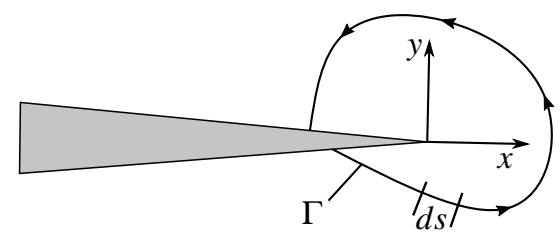

Figure 6: Arbitrary contour around the crack tip.

In the context of linear elasticity, the J-Integral is equal to the energy release rate during mixed-mode crack extension and is in $2 \mathrm{D}$ expressed as:

$$
J=G_{I}+G_{I I}
$$

In terms of SIFs, the J-Integral can be expressed by inserting Eq. 4 into Eq. 7 as:

$$
J=\alpha\left(K_{I}^{2}+K_{I I}^{2}\right) .
$$

Using the applicability of linear superposition in linear elasticity, two arbitrary stress states can be superimposed to get a third state:

$$
K_{I}^{(0)}=K_{I}^{(1)}+K_{I}^{(2)} ; \quad K_{I I}^{(0)}=K_{I I}^{(1)}+K_{I I}^{(2)},
$$

where the state is denoted by the superscript. Applying the superposition principle from Eq. 9 to Eq. 8 gives:

$$
J^{(0)}=\alpha\left(\left[K_{I}^{(1)}+K_{I}^{(2)}\right]^{2}+\left[K_{I I}^{(1)}+K_{I I}^{(2)}\right]^{2}\right) .
$$

Expanding the terms and comparing them to Eq. 8 gives:

$$
J^{(0)}=\underbrace{\alpha\left(K_{I}^{(1)^{2}}+K_{I I}^{(1)^{2}}\right)}_{J^{(1)}}+\underbrace{\alpha\left(K_{I}^{(2)^{2}}+K_{I I}^{(2)^{2}}\right)}_{J^{(2)}}+\underbrace{2 \alpha\left(K_{I}^{(1)} K_{I}^{(2)}+K_{I I}^{(1)} K_{I I}^{(2)}\right)}_{M^{(1,2)}},
$$

where the M-Integral is:

$$
\begin{aligned}
M^{(1,2)}=2 \alpha\left(K_{I}^{(1)} K_{I}^{(2)}+\right. & \left.K_{I I}^{(1)} K_{I I}^{(2)}\right) \\
& =\int_{\Gamma}\left(W^{(1,2)} d y-\left[T_{i}^{(1)} \frac{\partial u_{i}^{(2)}}{\partial x}+T_{i}^{(2)} \frac{\partial u_{i}^{(1)}}{\partial x}\right] d s\right)
\end{aligned}
$$

where $W^{(1,2)}$ is the mutual potential energy density: $W^{(1,2)}=\sigma_{i j}^{(1)} \varepsilon_{i j}^{(2)}=\sigma_{i j}^{(2)} \varepsilon_{i j}^{(1)}$ To determine unique solutions of $K_{I}$ and $K_{I I}$ two appropriate auxiliary solutions are to be 
chosen, namely: $K_{I}^{(2 a)}=1$ and $K_{I I}^{(2 a)}=0$, and $K_{I}^{(2 b)}=0$ and $K_{I I}^{(2 b)}=1$. Using auxiliary solution $(2 a)$ Eq. 12 can be solved for $K_{I}^{(1)}$ as:

$$
K_{I}^{(1)}=M^{(1,2 a)} / 2 \alpha=\int_{\Gamma}\left(W^{(1,2 a)} d y-\left[T_{i}^{(1)} \frac{\partial u_{i}^{(2 a)}}{\partial x}+T_{i}^{(2 a)} \frac{\partial u_{i}^{(1)}}{\partial x}\right] d s\right) / 2 \alpha
$$

where $T_{i}^{(1)}$ and $u_{i}^{(1)}$ are determined from the FE-solution and $T_{i}^{(2 a)}$ and $u_{i}^{(2 a)}$ by a known solution as, for example, the analytical solution derived by Westergaard [29]. The same procedure is applicable for auxiliary solution $(2 b)$ to calculate $K_{I I}$.

\subsection{Crystallographic crack propagation}

As discussed above, cracks in single-crystal nickel-base superalloys tend to grow on crystallographic $\{111\}$ planes. Since the crack path can deviate substantially from conventional Mode I cracks, the traditional approach to computing the SIFs on the crystallographic planes is not suitable and a new CDF measure needs to be introduced. The relation between crack propagation rate and SIF-range in Eq. 1 is usually based on the conventional Mode I SIF $K_{I}$ as CDF. This holds for most cases where the crack grows orthogonal to the maximum tensile stress, i.e. in most cases considering isotropic materials. In anisotropic materials like single-crystal nickel-base superalloys this is not necessarily valid, especially for crystallographic cracking. Thus, an appropriate CDF parameter is needed in order to predict cyclic crack growth in these materials in a similar fashion to Eq. 1. Most research suggests that shear stress intensity factors (as in $K_{I I}$ and $K_{I I I}$ ) resolved onto a crystallographic plane are suitable candidates [15, 18, 34-36]. This is motivated by the assumption that crystallographic cracking is coupled to the dislocation motion based on shearing, which is predominantly localized in the crystallographic planes.

\subsection{Crystallographic crack driving force}

The above presented M-Integral can be used to compute the SIFs in an anisotropic material. The anisotropic SIFs are then adopted to calculate the stress field around the crack tip using the definitions for anisotropic materials developed by Hoenig [37]. The stresses are then projected onto the slip plane into arbitrary directions of interest according to:

$$
\begin{aligned}
& k_{I}(\boldsymbol{n}, \boldsymbol{s})=\boldsymbol{n} \cdot \boldsymbol{\sigma}(\boldsymbol{s}) \cdot \boldsymbol{n} \\
& k_{I I}(\boldsymbol{n}, \boldsymbol{s})=\boldsymbol{s} \cdot \boldsymbol{\sigma}(\boldsymbol{s}) \cdot \boldsymbol{n} \\
& k_{I I I}(\boldsymbol{n}, \boldsymbol{s})=\boldsymbol{t} \cdot \boldsymbol{\sigma}(\boldsymbol{s}) \cdot \boldsymbol{n},
\end{aligned}
$$

where $\boldsymbol{n}$ is the unit normal of the crystallographic slip plane, $\boldsymbol{s}$ is the direction vector pointing towards the desired evaluation direction, $\boldsymbol{t}=\boldsymbol{s} \times \boldsymbol{n}$ and $\sigma$ is the stress tensor according to [37]. Note that the resolved SIF parameters are denoted by a lower case $k$ in 
order to distinguish it from the conventional SIF parameter $K$. The parameters $k_{I}, k_{I I}$ and $k_{I I I}$ correspond to the three modes of fracture resolved on an arbitrary plane in the given evaluation directions, $c f$. Fig. 7. A discussion about appropriate evaluation directions is given in Paper II. Based on the findings and previous research, one reasonable choice is to use the slip directions on the four crystallographic slip planes.

An equivalent CDF parameter $k_{E Q}$, accounting for resolved normal as well as resolved shear stresses, is formulated and is based on the idea that the resolved shear stresses weaken the crystallographic plane by dislocation motion and that the resolved normal stress separates the surfaces [18]:

$$
k_{E Q}=\sqrt{\psi_{I} k_{I}^{2}+\psi_{I I} k_{I I}^{2}+\psi_{I I I} k_{I I I}^{2}},
$$

where $\psi_{i}, i=1,2,3$, are calibration parameters that can be fitted based on experiments.

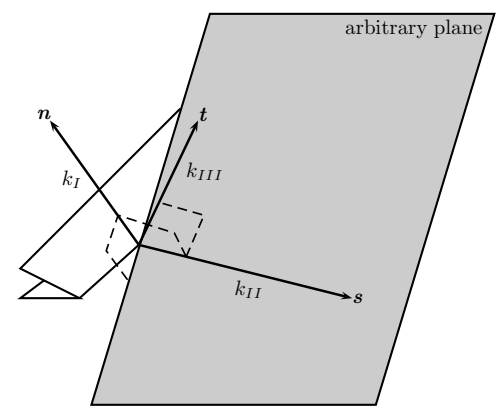

Figure 7: Illustration of the directions of the resolved SIFs

\subsection{FE-context}

The above presented crack propagation method is employed in a Finite-Element (FE) context to enable computations for arbitrary geometries, materials and load cases. A crack propagation software is used to automatically grow a crack through an FE-mesh based on the SIFs along the crack front. In order to be computationally more efficient, the FE-model is divided into a local and a global domain, where only the local domain is remeshed in each crack growth step to meet the current crack front shape and where the global domain retains its initial mesh. This method is employed in the crack propagation tool FRANC3D [38]. This tool is in this work used in conjunction with the FE-solver ABAQUS [39], which computes the displacement fields used by FRANC3D to calculate the SIFs by the above presented M-Integral. A schematic overview of the procedure is shown in Figure 8. A more detailed description of the procedure can be found in Paper III. For an anisotropic material, anisotropic SIFs are calculated along the crack front. These SIFs are then post-processed in order to calculate the resolved stress intensity factors $k_{I}$, $k_{I I}, k_{I I I}$ and $k_{E Q}$. 


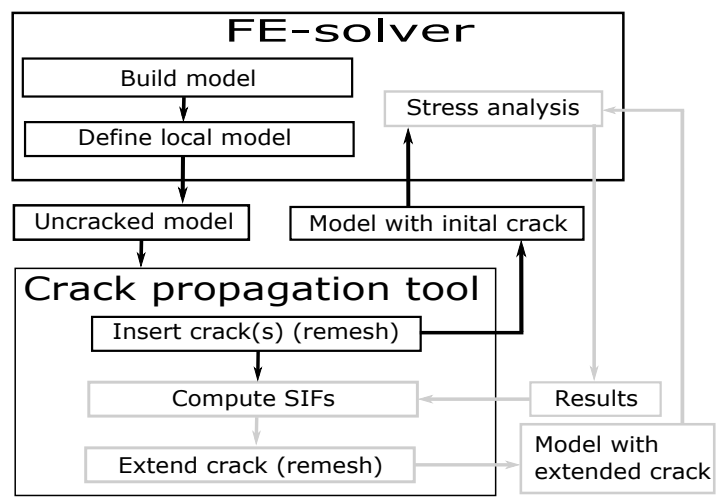

Figure 8: Workflow of crack propagation procedure

\subsection{Handling inelasticity}

For many applications it is important to know how to handle inelastic deformations around stress concentrations like notches, which can influence subsequent crack growth in the material by residual stresses. However, the approach to calculate the SIFs by the M-Integral is restricted to linear-elasticity, $c f$. Eqs. 7 and 9. A method of handling residual stresses caused by inelastic deformations in a linear elastic crack growth context is presented in Paper III. A residual stress field, which is extracted from the end of the first load cycles with a stable hysteresis of an uncracked FE-model in an elasto-plastic simulation, is superimposed to the linear elastic crack evaluation simulation of the cracked FE-model. This enables the possibility to account for inelastic deformations when using the M-Integral to calculate the SIFs. This approach is motivated by the assumption that after the initial shakedown no further inelastic deformations are accumulated. An appropriate material model has to be chosen in order to capture the correct inelastic behaviour, e.g. such as the one described in [3]. In Paper III, a method to utilize this material model in the M-integral context is presented. It should be noted, that the study in Paper III was done based on the material IN718 in polycrystalline form, but the methodology is expected to be applicable to arbitrary materials, i.e. also single-crystals. 



\section{Review of Appended Papers}

\section{Paper I}

A finite element study of the effect of crystal orientation and misalignment on the crack driving force in a single-crystal superalloy

A method is presented that enables the possibility to use a user defined single-crystal material model in a finite element-environment, which is paired with a crack growth tool. Crack evaluation simulations are performed in a three-dimensional context. The influence of the crystal orientation, as well as the influence of misalignments of the crystal orientation due to the casting process are investigated. It is shown that both the crystal orientation and the misalignment from the ideal crystal orientation are important for the crack driving force. It can be seen that crack growth behaviour is highly influenced by the misalignment.

\section{Paper II}

Prediction of crystallographic cracking planes in single-crystal nickel-base superalloys

Two different models to predict crystallographic cracking planes are presented. They enable the possibility to calculate anisotropic stress intensity factors resolved on crystallographic slip planes in a three-dimensional finite-element context, where crystallographic misalignments due to the casting process are accounted for. Furthermore, a method to account for inaccuracies during the determination of the crystallographic orientation is presented. The developed models have been compared to experiments of two different specimen geometries. The results show that a correct prediction of the crystallographic cracking plane could be achieved. 


\section{Paper III}

Three dimensional LEFM-prediction of fatigue crack propagation in a gas turbine disc material at component near conditions

A method is presented that accounts for plastic rearrangements of stresses and strains and its incorporation in crack propagation simulations in a linear elastic fracture mechanics context. In order to verify the results, they are compared to a series of LCF tests of notched specimens of the material Inconel 718. The tests involve high strain ranges compared to common fatigue crack propagation tests. In order to have a comparison, purely linear elastic simulations have been performed. The comparison of the stress intensity factors at the crack tip for different crack lengths and computation of the cyclic life-time shows that, for this test set-up, both approaches, i.e. the linear elastic and the method to account for plasticity, give good results close to the test data. 


\section{Outlook}

The next steps in this project are to predict how fast the crystallographic crack grows and apply the developed CDF parameter to predict when the cracking mode changes from Mode I cracking to crystallographic cracking, i.e. the prediction the of transition crack length. An overview of the project with the planned future work is given in Fig. 9.

The ambitious goal is to deliver a fatigue crack growth framework for single-crystal nickel-base superalloys which includes the developed crystallographic crack propagation model. This framework can then be implemented into the commercial software FRANC3D, which will be able to automatically grow a crack through a mesh, where the crack changes cracking mode, and to calculate the crystallographic crack driving force parameter without any user-input required.

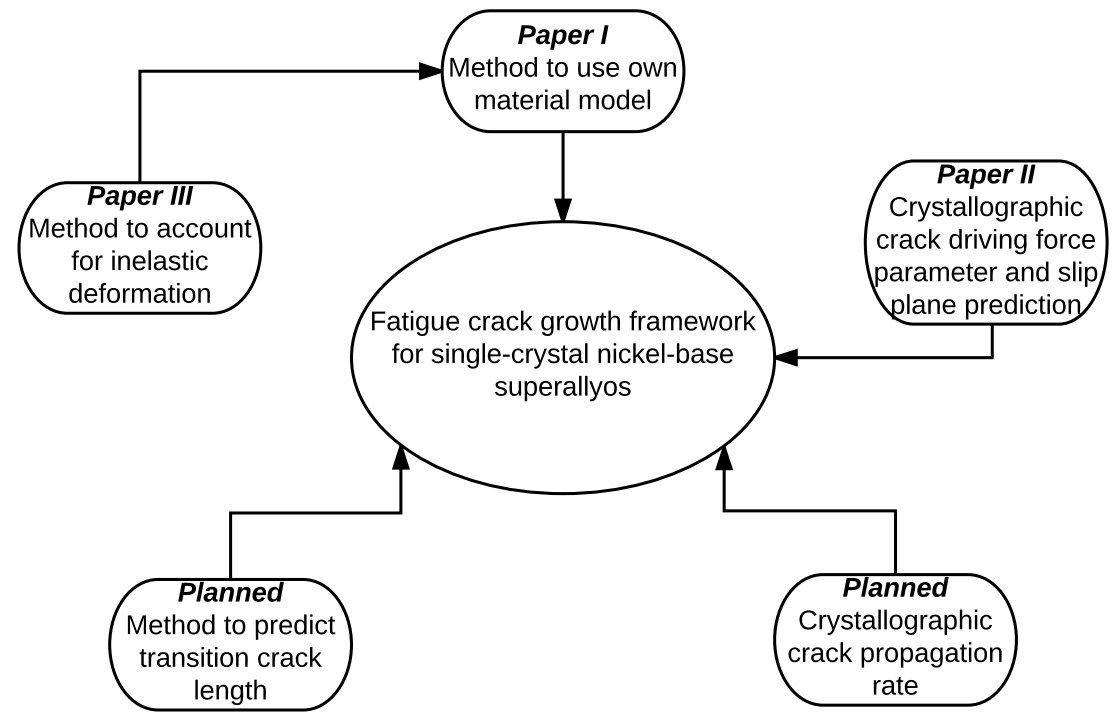

Figure 9: Overview of the planned project as a whole 



\section{Bibliography}

[1] International Energy Agency, World Energy Outlook 2015. 2015.

[2] R. Reed, The Superalloys-Fundamentals and Applications. Cambridge, UK: Cambridge University Press, 2006.

[3] D. Leidermark, J. Moverare, K. Simonsson, S. Sjöström, and S. Johansson, "Room temperature yield behaviour of a single-crystal nickel-base superalloy with tension/compression asymmetry," Computational Materials Science, vol. 47, no. 2, pp. 366-372, 2009.

[4] D. P. Pope and S. S. Ezz, "Mechanical properties of Ni3Al and nickel-base alloys with high volume fraction of gamma prime," International metals reviews, vol. 29, no. 3, pp. 136-167, 1984.

[5] M. Segersäll, J. Moverare, D. Leidermark, and K. Simonsson, Low-cycle fatigue behaviour of a Ni-based single-crystal superalloy, vol. 891-892. 2014.

[6] R. Naik, D. DeLuca, and D. Shah, "Critical plane fatigue modeling and characterization of single crystal nickel superalloys," Journal of Engineering for Gas Turbines and Power, vol. 126, no. 2, 2004.

[7] D. Leidermark and M. Segersäll, "Modelling of thermomechanical fatigue stress relaxation in a single-crystal nickel-base superalloy," Computational Materials Science, vol. 90, pp. 61-70, 2014.

[8] R. L. Amaro, S. D. Antolovich, R. W. Neu, and A. Staroselsky, "Physics-Based Modeling of Thermo-Mechanical Fatigue in PWA 1484," in Superalloys 2012, pp. 481-490, 2012.

[9] J. Moverare and R. Reed, "Thermomechanical fatigue in single crystal superalloys," in MATEC Web of Conferences, vol. 14, 2014.

[10] M. Segersäll, J. J. Moverare, D. Leidermark, and K. Simonsson, "Creep and stress relaxation anisotropy of a single-crystal superalloy," in Metallurgical and Materials Transactions A: Physical Metallurgy and Materials Science, vol. 45, pp. 2532-2544, 2014. 
[11] J.-B. Le Graverend, J. Cormier, F. Gallerneau, P. Villechaise, S. Kruch, and J. Mendez, "A microstructure-sensitive constitutive modeling of the inelastic behavior of single crystal nickel-based superalloys at very high temperature," International Journal of Plasticity, vol. 59, 2014.

[12] D. Leidermark, J. Moverare, K. Simonsson, and S. Sjöström, “A combined critical plane and critical distance approach for predicting fatigue crack initiation in notched single-crystal superalloy components," International Journal of Fatigue, vol. 33, no. 10, pp. 1351-1359, 2011.

[13] B. F. Antolovich, A. Saxena, and S. D. Antolovich, "Fatigue crack propagation in single-crystal CMSX- 2 at elevated temperature," Journal of Materials Engineering and Performance, vol. 2, no. 4, pp. 489-495, 1993.

[14] D. J. Duquette, M. Gell, and J. W. Piteo, "A Fractographic Study of Stage I Fatigue Cracking in a Nickel-Base Superalloy Single Crystal," Metallurgical Transactions, vol. 1, no. 11, pp. 3107-3115, 1970.

[15] T. Tinga, "Stress intensity factors and crack propagation in a single crystal nickelbased superalloy," Engineering Fracture Mechanics, vol. 73, no. 12, pp. 1679-1692, 2006.

[16] H. Kagawa and Y. Mukai, "The Effect of Crystal Orientation and Temperature on Fatigue Crack Growth of Ni-Based Single Crystal Superalloy,” pp. 225-233, John Wiley and Sons, oct 2012.

[17] K. S. Chan, J. Feiger, Y. D. Lee, R. John, and S. J. Hudak, "Fatigue crack growth thresholds of deflected mixed-mode cracks in PWA1484," vol. 127, pp. 2-7, jan 2005.

[18] J. Telesman and L. J. Ghosn, "Fatigue crack growth behavior of PWA 1484 single crystal superalloy at elevated temperatures," Journal of Engineering for Gas Turbines and Power, vol. 118, no. 2, pp. 399-405, 1996.

[19] M. Durand-Charre, The Microstructure of Superalloys. Amsterdam: Gordon and Breach Publishers, 1997.

[20] C. Busse, J. Homs, D. Gustafsson, F. Palmert, B. Sjödin, J. Moverare, K. Simonsson, and D. Leidermark, "A finite element study of the effect of crystal orientation and misalignment on the crack driving force in a single-crystal superalloy," in Proceedings of the ASME Turbo Expo, vol. 7A-2016, 2016.

[21] R. Reed, J. Moverare, A. Sato, F. Karlsson, and M. Hasselqvist, “A New Single Crystal Superalloy for Power Generation Applications," Superalloys 2012, pp. 197204, 2012.

[22] A. Sato, J. J. Moverare, M. Hasselqvist, and R. C. Reed, "On the Mechanical Behavior of a New Single-Crystal Superalloy for Industrial Gas Turbine Applications," Metallurgical and Materials Transactions A, vol. 43, no. 7, pp. 2302-2315, 2012. 
[23] A. Coles, R. E. Johnson, and H. G. Popp, "Utility of surface-flawed tensile bars in cyclic life studies," Journal of Engineering Materials and Technology, Transactions of the ASME, vol. 98, no. 4, pp. 305-315, 1976.

[24] ASTM, "Test Method for Measurement of Fatigue Crack Growth Rates," tech. rep., 2012.

[25] N. Hou, W. Gou, Z. Wen, and Z. Yue, "The influence of crystal orientations on fatigue life of single crystal cooled turbine blade," Materials Science and Engineering: A, vol. 492, no. 1-2, pp. 413-418, 2008.

[26] M. Segersäll, D. Leidermark, and J. J. Moverare, "Influence of crystal orientation on the thermomechanical fatigue behaviour in a single-crystal superalloy," Materials Science and Engineering A, vol. 623, pp. 68-77, 2015.

[27] P. C. Paris, M. P. Gomez, and W. E. Anderson, "A Rational Analytic Theory of Fatigue," The trend in Engineering, vol. 13, pp. 9-14, 1961.

[28] P. C. Paris and F. Erdogan, "A Critical Analysis of Crack Propagation Laws," 1963.

[29] H. M. Westergaard, "Bearing pressures and cracks," 1939.

[30] G. Irwin, "Onset of Fast Crack Propagation in High Strength Steel and Aluminum Alloys," Sagamore Research Conference Proceedings, no. May 1956, pp. 289-305, 1956.

[31] J. F. Yau, S. S. Wang, and H. T. Corten, "A Mixed-Mode Crack Analysis of Isotropic Solids Using Conservation Laws of Elasticity," Journal of Applied Mechanics, vol. 47, no. 2, p. 335, 1980.

[32] P. A. Wawrzynek, B. J. Carter, and L. Banks-Sills, The M-integral for computing stress intensity factors in generally anisotropic materials. Huntsville, USA: NASA, Marshall Space Flight Center, 2005.

[33] L. Banks-Sills, P. A. Wawrzynek, B. Carter, A. R. Ingraffea, and I. Hershkovitz, "Methods for calculating stress intensity factors in anisotropic materials: Part IIArbitrary geometry," Engineering Fracture Mechanics, vol. 74, no. 8, pp. 12931307, 2007.

[34] M. Gell and G. Leverant, "The characteristics of stage I fatigue fracture in a highstrength nickel alloy,” Acta Metallurgica, vol. 16, no. 4, pp. 553-561, 1968.

[35] S. Ranjan and N. K. Arakere, "A Fracture-Mechanics-Based Methodology for Fatigue Life Prediction of Single Crystal Nickel-Based Superalloys," Journal of Engineering for Gas Turbines and Power, vol. 130, no. 3, p. 032501, 2008.

[36] W. Qiu, X. Ma, S. Rui, and H.-J. Shi, "Crystallographic analysis on small fatigue crack propagation behaviour of a nickel-based single crystal superalloy," Fatigue and Fracture of Engineering Materials and Structures, vol. 40, no. 1, 2017. 
[37] A. Hoenig, "Near-tip behavior of a crack in a plane anisotropic elastic body," Engineering Fracture Mechanics, vol. 16, no. 3, pp. 393-403, 1982.

[38] FRANC3D, FRANC3D Reference Manual. Ithaca, USA: Fracture Analysis Consultants Inc., 2016.

[39] ABAQUS, ABAQUS 6.12 Documentation. Providence, USA: Dassault Systèmes, 2014. 


\section{Appended Papers}

The papers associated with this thesis have been removed for copyright reasons. For more details about these see:

http:// urn.kb.se/ resolve?urn=urn:nbn:se:liu:diva-143058 